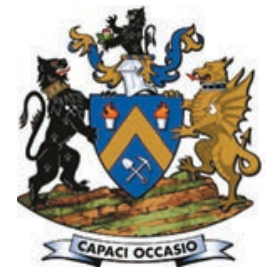

Affiliation:

${ }^{1}$ Mining and Mineral Resources, Mining Cluster, CSIR, Johannesburg, South Africa.

2 School of Human Movement Sciences, North-West University, Potchefstroom Campus, South Africa.

Correspondence to: J. Hodgskiss

Email:

JHodgskiss@csir.co.za

Dates:

Received: 12 Dec. 2019

Revised: 3 Jul. 2020

Accepted: 7 Jul. 2020

Published: May 2020

\section{How to cite:}

Pelders, J.J. and de Ridder, J.H. Assessment of the ergonomic design of self-contained self-rescuer (SCSR) devices for use by women in mining.

The Southern African Insitute of Mining and Metallurgy

DOI ID:

http://dx.doi.org/10.17159/24119717/1054/2020

ORCiD ID:

J.J. Pelders

https://orchid.org/0000-0003-

4671-1951

ORCID ID:

J.H. de Ridder

https://orchid.org/0000-00018766-8916

This paper was first presented at the International Health and Safety Conference 2019, 31 October-1 November 2019 Misty Hills Country Hotel \& Conference Centre, Muldersdrift, Johannesburg, South Africa.

\title{
Assessment of the ergonomic design of self-contained self-rescuer (SCSR) devices for use by women in mining
}

\author{
J.J. Pelders ${ }^{1}$ and J.H. de Ridder ${ }^{2}$
}

\begin{abstract}
Synopsis
Increasing numbers of women are entering the South African mining industry, but self-contained self-rescuer (SCSR) devices might not be suited to female anthropometric dimensions. The aim of this project was to assess the ergonomic design of SCSRs for use by women in the SAMI. Body measurements and questionnaires were collected from 100 female mineworkers from one coal, one platinum, and one gold mine in South Africa. Practical performance assessments of SCSRs when worn on the belt and when donned and in use were conducted with 11 female mineworkers in a simulated underground mining environment. The majority of the participants experienced pain or discomfort when wearing an SCSR and numerous anthropometric dimensions differed from reference values. Dimensional limitations or shortcomings of current SCSRs for use by women in mining were identified, including that the devices were considered to be too heavy and bulky for daily wearing on the belt.

The study findings can be used to inform interventions to improve the design and fit of SCSRs.
\end{abstract}

\section{Keywords}

anthropometry, personal protective equipment, respiratory protective devices, South African mining industry, women in mining.

\section{Introduction}

Body-worn self-contained self-rescuers (SCSRs) are part of the personal protective equipment (PPE) required in coal mines and high-risk areas in hard rock mines (SANS1737:2008; Schreiber, 1999). These devices are designed to be worn on the body for the complete duration of a working shift (SANS1737:2008; Schreiber, 1999). They are used in case of emergency situations, such as fires or gas inundations, to protect the user from contaminants in the ambient air and to provide breathable air for a sufficient amount of time to allow the worker to exit safely from the mine or reach a place of safety (Kowalski-Trakofler et al., 2008; Sandström, 2015; Schreiber et al., 2003; Schutte et al., 2005; Teeravarunyou, 2008). Schreiber and Sehlabana (2015) reported that there were four makes of SCSRs deployed in the South African mining industry. The rated durations of these devices range from 25 to 40 minutes, the weights of the unopened units range from $2.1 \mathrm{~kg}$ to $2.5 \mathrm{~kg}$, and the average heights, widths and depths of the units are $202 \mathrm{~mm}, 185 \mathrm{~mm}$ and $104 \mathrm{~mm}$, respectively (Afrox, 2014; Drägersafety, 2010; MSA, 2016; Schauenburg Lighting Technologies, 2013). Some of the side-effects of wearing SCSRs include discomfort, restriction of movement, and physical load (Bakri et al., 2012; Coca et al., 2011; ISO/TS 16976-8:2013; Zungu, 2012).

Although the mining industry is historically male-dominated, there has been an increase in the number of women entering the South African mining industry as a result of regulations such as the Mining Charter and the Minerals and Petroleum Resources Development Act 28 of 2002 (South Africa, 2002a and 2002b; Zungu, 2012). Women have different anatomical and physiological characteristics than men (van Aardt et al., 2012; Zungu, 2013). However, PPE has generally been designed based on male anthropometric dimensions (Anglo American, 2012; van Aardt et al., 2008; Zungu, 2013). As a result, women's comfort, safety and performance at work may be compromised (van Aardt et al., 2008; Zungu, 2012). Further research on the compatibility of PPE, including SCSR devices, for use by women in mining is therefore warranted.

The implementation of ergonomics principles during the design and manufacture of any article for use at a mine is mandated in the Mine Health and Safety Act (Act 29 of 1996) (South Africa, 1996). The goal of ergonomics is to ensure that tasks, jobs, products, machines, equipment, environments, and systems are suited to people in order to improve their health, safety, productivity, and well-being (International Ergonomics Association, 2016; ISO/TS 16976-8: 2013; Schutte, 2005; Schutte and James, 


\section{Assessment of the ergonomic design of self-contained self-rescuer (SCSR) devices}

2007; Schutte and Shaba, 2003). Anthropometry is a branch of ergonomics, and refers to the scientific procedures and processes of acquiring surface anatomical dimensional measurements such as lengths, breadths, girths, and skinfolds of the human body by means of specialist equipment (Stewart et al., 2011). Anthropometric data are required for the appropriate design of SCSRs (ISO/TS 16976-2: 2015; Schutte and Shaba, 2003). The aim of this study was to assess the ergonomic design of SCSR devices for use by women in the South African mining industry, in order to identify improvements that would make the wearing of SCSR devices more acceptable, comfortable for the wearer, and not impede escape. This paper was derived from the report for a study commissioned by the Mine Health and Safety Council (project number: SIM 160902, Hodgskiss et al., 2017).

\section{Methods}

This project employed mixed methods as both qualitative and quantitative data were collected. The research was crosssectional, and data collection took place between February and April 2017. The research comprised two components, namely an anthropometric assessment of women working at mines in South Africa and a practical ergonomics performance assessment. Ethical approval to conduct this research was obtained by the CSIR Research Ethics Committee (Ref: 179/2016).

The anthropometric assessment took place at one coal, one platinum, and one gold mine in South Africa. These mines were located in the provinces of Mpumalanga, Limpopo and Gauteng, respectively, and each mine made use of a different model of SCSR. The mines were purposively selected, based on knowledge and understanding of the project team, and permissions received to access the sites. The participants were selected on a convenience basis, according to availability and due to the voluntary nature of the research. A total of 100 female mineworkers participated. Although the sample could not be fully representative, workers from a range of locations and demographic characteristics were included in the study. Anthropometric measurements were taken from 27 body sites according to the International Society for the Advancement of Kinanthropometry (ISAK) standards (Stewart et al., 2011). In addition, body mass index (BMI) and waist-to-hip ratio were calculated. The identified measurements were selected primarily with reference to ISO/TS 16976-2:2015 (Part 2) and ISO/CD 16900-5.2 (Part 5). Participants also completed questionnaires to provide information on demographic characteristics and subjective responses relating to the comfort of SCSRs. Despite its potential limitations, the use of subjective data enabled the gathering of data relating to the experiences of workers that might not be measurable when using other methods. Researchers fluent in local languages were available to assist the participants.

The practical ergonomics assessment involved an analysis of the use of approved SCSRs by women when navigating a test route. The participants for this project component were recruited from a coal mine and a metalliferous mine to ensure representation of these different mine types and the associated occupations. The platinum mine was selected as the metalliferous mine, although a gold mine would also have been appropriate. The study sample comprised of 11 female mineworkers, who usually worked underground and were required to wear SCSRs for their daily tasks. Initially, six participants were selected from each mine. However, one of the participants from the coal mine was unable to attend both days of testing, due to work requirements, therefore participant's results were excluded.
The practical ergonomics assessment was undertaken in a simulated underground mining environment, as per sub clause 5.2.9.1 of SANS 1737:2008. The participants were required to complete a predetermined test route that involved upright walking on level and sloped surfaces, stooped walking, crawling, and going up and down stairs. A control session involved the participants having to navigate the route while wearing normal PPE, but without an SCSR. Testing sessions involved navigating the route wearing each of four approved SCSR models on the belt and while donned and activated. Prior to testing, the correct procedures for opening, donning, and using each make of escape apparatus were demonstrated in accordance with the manufacturer's instructions. Data collected included environmental temperature, oral body temperatures, test duration, ratings of perceived exertion (RPE) (Borg, 1962), and body discomfort (Corlett and Bishop, 1976). The ergonomic assessment questionnaire as included in SANS 1737:2008 was completed, and observations and photographic recordings were also made.

Data was captured electronically and analysed. Descriptive and comparative statistical analyses were performed on the quantitative data, at a significance level of $p<0.05$. Averages, standard deviations (SDs), minimum and maximum values, and percentiles were determined for each anthropometric variable, which were compared against ISO reference values, using the one-sample median test. For the practical ergonomic assessment, comparisons were made of responses obtained during the control session, when the units were worn on the belt, and when donned and in use. Comparisons of responses while using the different SCSR models were also made.

\section{Results}

\section{Anthropometric assessment}

Demographic information and comfort ratings were obtained from questionnaires completed by 91 of the participants. The average age of the participants was 34.9 (SD: 7.5), ranging from 19 to 57 years. Most of the participants were South African (95\%) and $98 \%$ were Black. Almost all of the participants (99\%) considered the SCSR devices to be too heavy, and $92 \%$ reported that they disturbed their work.

The majority of the participants reported discomfort while wearing SCSRs on the belt during their daily work, with $68 \%$ reporting that this occurred most or all the time (Figure 1). The body areas where the most discomfort was experienced were the lower back, hips, and stomach (abdomen) (Figure 2). Participants commented that they hoped the SCSRs could be made smaller, lighter, and more comfortable.

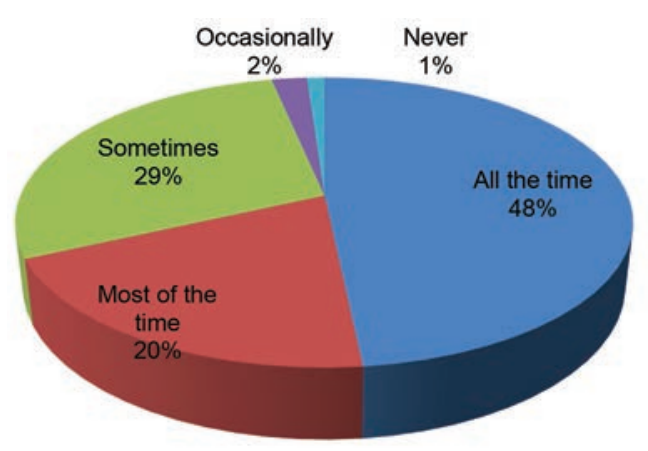

Figure 1-Frequency of pain or discomfort when wearing an SCSR 


\section{Assessment of the ergonomic design of self-contained self-rescuer (SCSR) devices}

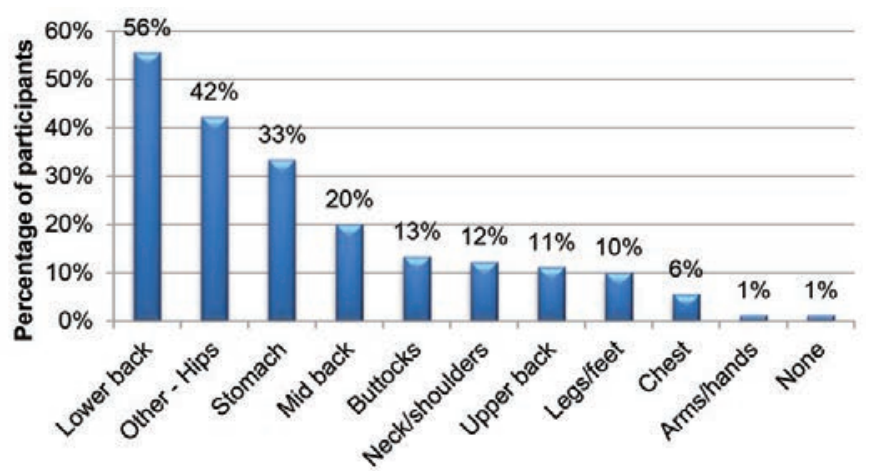

Figure 2-Area of body with pain or discomfort when wearing an SCSR
Anthropometric measurements were obtained from 98 participants. Anthropometric data, including the average, SD, and 5th, 50th and 95th percentiles, for the 27 measurements as well as the derived indices of BMI and waist-to-hip ratio is shown in Table I. The data was compared with torso reference values from ISO/CD 16900-5.2 and ISO/TS 16976-2:2015 for males and females, and for females only, to assess whether the data used for design and testing of SCSRs was suited to women. Numerous significant differences were evident (Table I). As expected, most of the reference values, such as for height measurements, were larger than the average measurements from our study, as our study only included female participants. The measurements for which the study sample had higher averages than the

\section{Table I}

Anthropometric data for the study sample compared with reference and previous study data*

\begin{tabular}{|c|c|c|c|c|c|c|c|c|c|c|c|}
\hline & \multirow[b]{2}{*}{ Measurement } & \multicolumn{8}{|c|}{ Study data } & \multicolumn{2}{|c|}{ Reference data } \\
\hline & & $\mathbf{N}$ & Average & $\begin{array}{l}\text { Standard } \\
\text { deviation }\end{array}$ & Minimum & Maximum & $\begin{array}{c}\text { 5th } \\
\text { percentile }\end{array}$ & $\begin{array}{c}\text { 95th } \\
\text { percentile }\end{array}$ & $\begin{array}{c}50 \text { th } \\
\text { percentile }\end{array}$ & $\begin{array}{c}\text { ISO data } \\
\text { 50th percentile } \\
\text { (males and females) }\end{array}$ & $\begin{array}{c}\text { ISO data } \\
\text { 50th percentile } \\
\text { (females only) }\end{array}$ \\
\hline 1 & Stature $(\mathrm{cm})$ & 98 & 160.2 & 5.6 & 147.1 & 172.4 & 150.8 & 168.4 & 160.4 & 169.1 & 162.7 \\
\hline 2 & Weight (kg) & 98 & 76.3 & 15.3 & 49.2 & 121.2 & 52.8 & 101.5 & 75.9 & 80.3 & 72.1 \\
\hline 3 & Sitting height $(\mathrm{cm})$ & 93 & 81.6 & 3.1 & 74.9 & 90.3 & 77.0 & 86.9 & 81.5 & - & - \\
\hline 4 & Head circumference $(\mathrm{cm})$ & 90 & 58.2 & 3.3 & 52.0 & 69.5 & 53.6 & 63.7 & 57.7 & 56.5 & 55.5 \\
\hline 5 & Neck circumference $(\mathrm{cm})$ & 90 & 33.2 & 1.9 & 29.0 & 38.4 & 29.9 & 36.2 & 33.2 & 36.9 & 33.5 \\
\hline 6 & Head length $(\mathrm{cm})$ & 91 & 19.1 & 2.0 & 12.7 & 23.2 & 14.0 & 21.5 & 19.4 & 19.2 & 18.7 \\
\hline 7 & Maximum head breadth $(\mathrm{cm})$ & 92 & 13.7 & 1.7 & 8.9 & 17.1 & 9.8 & 15.7 & 14.0 & 15.0 & 14.6 \\
\hline 8 & Menton-sellion length $(\mathrm{cm})$ & 88 & 11.0 & 0.6 & 9.5 & 12.4 & 10.1 & 11.9 & 11.0 & 11.8 & 11.3 \\
\hline 9 & Interpupillary distance $(\mathrm{cm})$ & 92 & 6.2 & 0.5 & 4.6 & 7.5 & 5.3 & 6.8 & 6.2 & 6.35 & 6.2 \\
\hline 10 & Eye-to-nose diagonal (cm) & 91 & 4.5 & 0.9 & 2.8 & 7.6 & 3.4 & 6.0 & 4.4 & - & - \\
\hline 11 & Nose breadth $(\mathrm{cm})$ & 91 & 4.0 & 0.3 & 3.0 & 4.7 & 3.4 & 4.5 & 4.0 & 3.45 & 3.3 \\
\hline 12 & $\begin{array}{l}\text { Top of breastbone to centre of } \\
\text { mouth }(\mathrm{cm})\end{array}$ & 91 & 13.0 & 1.7 & 8.4 & 16.8 & 10.4 & 16.0 & 13.0 & - & - \\
\hline 13 & $\begin{array}{l}\text { Height of prominent neck vertebra, } \\
\text { sitting }(\mathrm{cm})\end{array}$ & 87 & 60.4 & 2.7 & 55.2 & 66.6 & 55.9 & 64.6 & 60.2 & 64.8 & 62.8 \\
\hline 14 & $\begin{array}{l}\text { Shoulder (acromion) height, } \\
\text { sitting (cm) }\end{array}$ & 87 & 53.9 & 2.8 & 48.4 & 62.2 & 49.8 & 59.3 & 53.8 & 58.7 & 56.9 \\
\hline 15 & Mid-shoulder height, sitting $(\mathrm{cm})$ & 87 & 39.6 & 3.2 & 33.9 & 55.7 & 35.1 & 44.8 & 39.8 & 60.6 & 57.9 \\
\hline 16 & Shoulder breadth (deltoid) $(\mathrm{cm})$ & 87 & 42.3 & 3.0 & 36.3 & 51.9 & 37.5 & 46.7 & 42.2 & 43.7 & 41.6 \\
\hline 17 & Chest breadth, at level of nipples $(\mathrm{cm})$ & 87 & 29.5 & 2.9 & 22.9 & 37.2 & 25.6 & 35.4 & 29.2 & 30.6 & 28.2 \\
\hline 18 & Chest depth (cm) & 87 & 23.0 & 3.6 & 17.2 & 33.6 & 17.8 & 29.4 & 23.0 & 25.0 & 25.1 \\
\hline 19 & Chest circumference $(\mathrm{cm})$ & 87 & 99.9 & 11.2 & 78.6 & 126.5 & 85.0 & 120.2 & 99.8 & 91.9 & 92.1 \\
\hline 20 & $\begin{array}{l}\text { Trunk height to the top of the breast } \\
\text { percentile }\end{array}$ & 92 & 54.4 & 2.9 & 48.5 & 61.8 & 49.4 & 59.2 & 54.3 & 58.5 & 57.3 \\
\hline 21 & $\begin{array}{l}\text { Height of maximum lumbar curvature, } \\
\text { sitting }(\mathrm{cm})\end{array}$ & 92 & 21.4 & 5.2 & 11.2 & 34.1 & 13.3 & 29.2 & 20.8 & 23.7 & 23.2 \\
\hline 22 & Sitting hip height $(\mathrm{cm})$ & 92 & 22.1 & 2.5 & 13.5 & 29.1 & 18.7 & 26.6 & 21.8 & - & - \\
\hline 23 & Lower abdominal depth $(\mathrm{cm})$ & 92 & 25.3 & 5.2 & 15.9 & 37.7 & 17.8 & 33.2 & 24.3 & 26.7 & 25.0 \\
\hline 24 & Waist breadth $(\mathrm{cm})$ & 92 & 30.5 & 4.5 & 20.1 & 43.2 & 24.2 & 38.3 & 30.0 & 26.2 & 26.4 \\
\hline 25 & Hip breadth $(\mathrm{cm})^{\star *}$ & 92 & 33.9 & 5.8 & 22.9 & 63.3 & 26.0 & 41.5 & 33.8 & 32.4 & 32.1 \\
\hline 26 & $\begin{array}{l}\text { Waist circumference - natural } \\
\text { sitting }(\mathrm{cm})\end{array}$ & 96 & 84.7 & 11.8 & 52.5 & 107.6 & 67.1 & 103.0 & 84.8 & 80.4 & 76.9 \\
\hline 27 & Mid-hip circumference $(\mathrm{cm})$ & 96 & 110.5 & 11.9 & 83.1 & 145.0 & 92.2 & 130.3 & 110.5 & 105.8 & 105.6 \\
\hline 28 & BMI $\left(\mathrm{kg} / \mathrm{m}^{2}\right)$ & 98 & 29.8 & 5.8 & 19.9 & 43.7 & 21.4 & 39.9 & 29.6 & 23.7 & 22.2 \\
\hline 29 & Waist-to-hip ratio & 96 & 0.77 & 0.07 & 0.42 & 0.94 & 0.67 & 0.88 & 0.77 & 0.76 & 0.73 \\
\hline
\end{tabular}




\section{Assessment of the ergonomic design of self-contained self-rescuer (SCSR) devices}

reference values were for head circumference, nose breadth, chest circumference, waist breadth, waist circumference and hip circumference, along with BMI and waist-to-hip ratio. The differences in data collected versus reference data indicates that the dimensions used in the design of such equipment may not be appropriate for the assessed population.

\section{Practical performance assessment}

The use of SCSR devices by women in the South African mining industry was assessed in a simulated underground test route. The average age of the 11 participants was 31.1 years (SD: 4.4, range: 26-41), the average stature was $163.5 \mathrm{~cm}$ (SD: $4.3 \mathrm{~cm}$, range: $157-171 \mathrm{~cm}$ ), and the average weight was $76.9 \mathrm{~kg}$ (SD: $17.4 \mathrm{~kg}$, range: $62-121 \mathrm{~kg}$ ). The average time taken to navigate the test route with the SCSR worn on the belt was 10 minutes 15 seconds, and 10 mininutes 52 seconds while donned and in use. The average time to complete donning and adjusting the units was 2 minutes 32 seconds, which was longer than the expected time of only a few seconds before breathing safely through the unit.

Ratings of perceived exertion (RPE) and body discomfort were provided by the participants. The RPE scale ranges from 6 ('very, very light') to 20 ('very, very hard') for both central (heart and lung) and peripheral (muscular) exertion. Greater exertion was evident when an SCSR was worn on the belt than when no SCSR was worn, and the highest levels of exertion were evident when the SCSRs were donned and in use (Figure 3).

A body discomfort map was used on which participants indicated where they felt discomfort, along with the level of discomfort experienced for each area, on a scale from 1 ('very slight discomfort') to 10 ('extreme discomfort'). None of the participants reported discomfort after completion of the control route. Discomfort while the units were worn on the belt was mainly experienced in the lower back, hips, and quadriceps (Figure 4). The highest comfort ratings for wearing the units on the belt were reported for the units that were smaller, lighter, and contoured to fit the wearer's body. When the units were donned and in use, the participants experienced discomfort mostly in the neck, shoulders, jaws, teeth, throat, and chest (Figure 5). The participants experienced the highest levels of neck and jaw strain when a model that was worn on the head rather than on the chest was donned.

The participants completed an ergonomic assessment questionnaire to rate the SCSRs on various aspects on a scale from 0 ('totally unacceptable') to 10 ('highly acceptable'). The average scores for the main categories of 'ergonomic design for normal wearing' (i.e. wearing the SCSR on the belt), 'ergonomic design for donning', and 'ergonomic design for negotiating

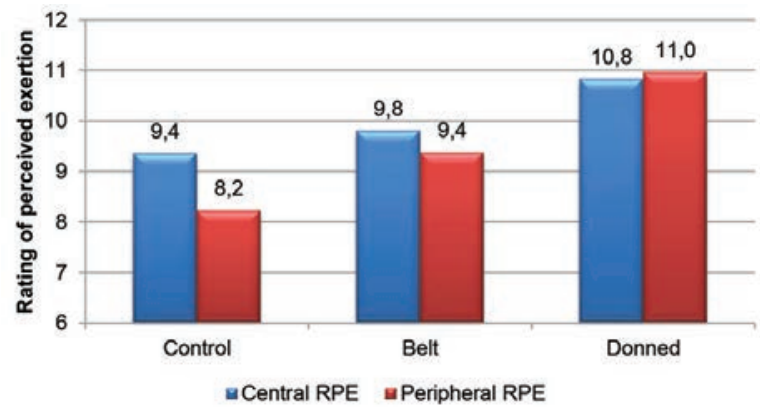

Figure 3-Average central and peripheral ratings of perceived exertion (RPE)

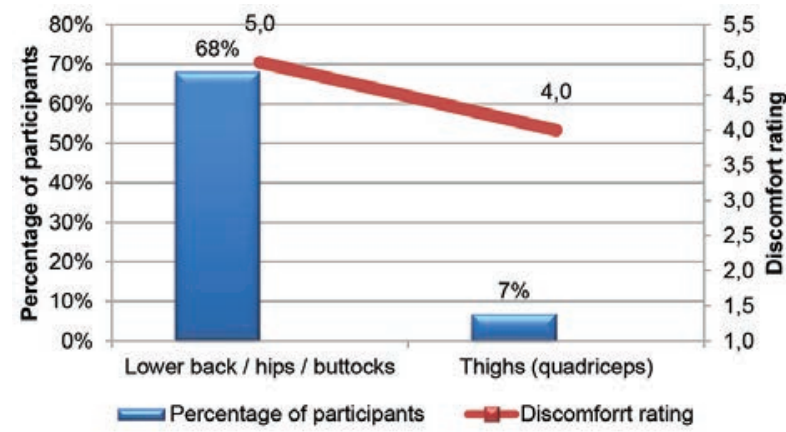

Figure 4-Average body discomfort while wearing SCSRs on the belt

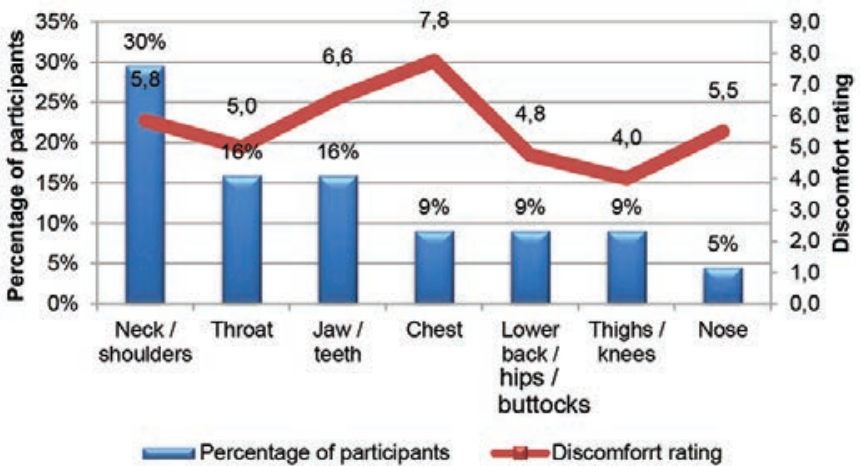

Figure 5-Average body discomfort while SCSRs were donned and in use

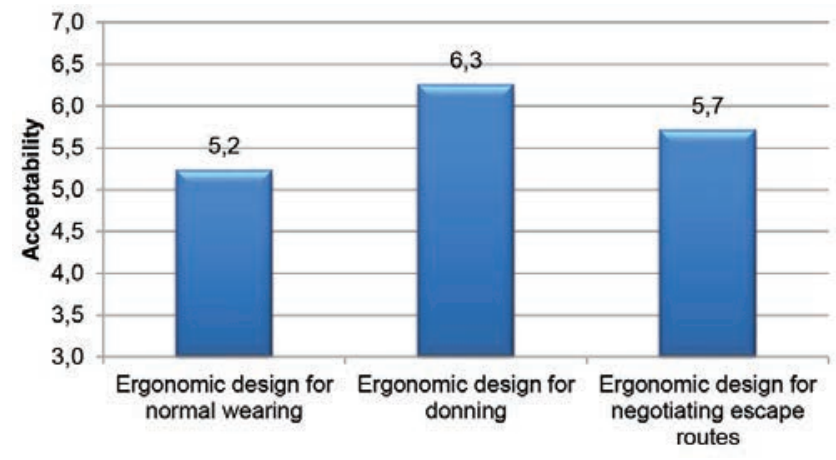

Figure 6-Ratings of the ergonomic design of SCSRs

escape routes' are shown in Figure 6. Although these average scores were considered acceptable (a score of 5 or above), the average scores for some of the SCSR models were 5 or below, and there was variability in the responses between participants. The average scores for each question are shown in Table II.

In general, it was perceived that the shape and weight of the SCSRs were not suitable for normal wearing. The suitability of the belts worn by the participants appeared to influence the results, and it was evident that the SCSRs sometimes slipped around the belt when the participants navigated the test route (e.g. when crawling).

The ergonomic design for donning of the SCSRs was, on average, rated as acceptable. However, some of the participants experienced difficulty in opening the protective casings of the SCSRs, and with locating and adjusting the straps. When the SCSRs were donned and in use, the lowest score was for the comfort of the nose-clips (which are to prevent breathing in of toxic gases) as these were often noted as causing pain. 
Table II

Ratings of the ergonomic design of SCSRs

\begin{tabular}{|c|c|c|}
\hline & Category & Average \\
\hline $\begin{array}{l}\text { Ergonomic design } \\
\text { for normal wearing }\end{array}$ & $\begin{array}{l}\text { (a) Shape of escape apparatus (shaped to body contours, comfort) } \\
\text { (b) Size of escape apparatus (too bulky for routine work, or only if in confined spaces; bruising, bumping, catching) } \\
\text { (c) Mass of escape apparatus (are you aware of the mass of the escape apparatus, and if so how would you rate it?) } \\
\text { (d) Wearing arrangement - belt and suspension to belt (comfort in negating the effect of mass?) } \\
\text { (e) Daily affixing of escape apparatus to the body (cumbersome?) } \\
\text { (f) Prevention of accidental opening of escape apparatus }\end{array}$ & $\begin{array}{l}4.7 \\
5.1 \\
4.0 \\
5.6 \\
5.0 \\
7.0\end{array}$ \\
\hline $\begin{array}{l}\text { Ergonomic design } \\
\text { for donning }\end{array}$ & $\begin{array}{l}\text { (a) Ease of manoeuvring escape apparatus into donning position } \\
\text { (b) Ease of opening the container } \\
\text { (c) Ease of handling essential parts: } \\
\text { i. Breathing tube } \\
\text { ii. Insertion of mouthpiece } \\
\text { iii. Fixing of nose clip } \\
\text { (d) Ease of affixing and adjusting of ancillary webbing/equipment: } \\
\text { i. Head strap } \\
\text { ii. Bag strap } \\
\text { iii. Body strap }\end{array}$ & $\begin{array}{l}7.1 \\
6.1\end{array}$ \\
\hline $\begin{array}{l}\text { Ergonomic design for } \\
\text { negotiating escape routes }\end{array}$ & $\begin{array}{l}\text { (a) Accommodation for different torso lengths and sizes in respect of breathing tube and ancillary webbing, etc. } \\
\text { (b) Comfort } \\
\text { i. Nose-clip } \\
\text { ii. Mouthpiece } \\
\text { iii. Physical contact of set with body - too hot? } \\
\text { iv. Breathing resistance } \\
\text { v. Breathing temperature }\end{array}$ & $\begin{array}{l}5.8 \\
4.7 \\
5.4 \\
5.7 \\
6.3 \\
6.3\end{array}$ \\
\hline
\end{tabular}

The breathing tubes for some of the units appeared to be too short to comfortably accommodate all of the users. Some of the participants also commented that the SCSRs were a bit loose on the body, which could relate to how the units were fitted and the straps adjusted. Some noted that their vision was obscured when the SCSRs were donned and in use. The participants commented that they experienced neck, jaw, and tooth strain when the unit with the head (rather than neck) straps was donned, as the weight of the unit was borne by the neck and jaw rather than resting on the chest. Some noted increases in breathing resistance and air temperature when using the SCSRs, and some experienced headaches. It was possible that the units would heat up further with longer durations of use and potentially burn the chin or chest.

\section{Conclusion and recommendations}

The ergonomic design of SCSR devices for use by women in the South African Mining Industry was assessed. It was evident that women in the SAMI experienced pain and discomfort while wearing an SCSR on the belt during their daily work, particularly in the hips, lower back, and abdomen. Most considered the SCSRs to be too heavy, and indicated that they disrupted their work. Results of the anthropometric assessment indicated that data used in the design of SCSRs might not be appropriate for women. Findings from the practical ergonomics assessment showed that the lowest strain was experienced when no SCSR was worn, higher strain was experienced when the SCSRs were worn on the belt, and the highest strain was experienced when the SCSRs were donned and in use. The study findings indicated the need for improved ergonomic design of SCSRs for use by women in the South African mining industry.

Recommendations to improve the ergonomic design of SCSRs for use by women were compiled with input from stakeholders and subject matter experts. The findings of the project were presented during a workshop for this purpose, and proposed recommendations were discussed and revised, based on the feedback received. As many of the factors highlighted appeared to be general, rather than specific to females, recommendations to improve the ergonomics of SCSRs for women in mining might also be expected to apply to male mineworkers. Recommended interventions to improve the design and fit of SCSRs include:

> Make SCSRs lighter and smaller, as far as practically possible

> Shape SCSRs to the contours of the body

- Consider changes to the casing material of SCSRs

- Ensure ease of locating parts of the SCSR when donning

> Avoid the use of head-mounted units in future developments

- Ensure adequate length of breathing tubes

> Ensure adequate adjustability of neck and body straps

- Ensure optimal design of SCSR goggles

> Consider changes to the wearing arrangement of SCSRs.

Related recommendations that were indicated to have high priority as 'quick-win' solutions were:

- Ensure the provision of specific belts recommended by the respective OEMs

> Implement experiential and expectation training for the donning and use of SCSRs.

Further recommended research included:

- A comparative ergonomics study of males in the SAMI:

> The assessment of proposed interventions and developments

- Reassessment of the escape strategies of mines for female mine workers.

Appropriate implementation of the recommendations would assist with the development of interventions to improve health, safety, and productivity in the mining industry. 


\section{Assessment of the ergonomic design of self-contained self-rescuer (SCSR) devices}

\section{Acknowledgements}

We would like to thank the following people or institutions for their valuable contributions during the research project:

> The Mine Health and Safety Council (MHSC) for commissioning the research

> The participating mines for their support and all of the participants for their involvement, without which the research could not have taken place

> Mines Rescue Services for the use of its services and facilities

> The original equipment manufacturers (OEMs) for providing the SCSR devices for use in the study, for the demonstrations of donning procedures and for their involvement in discussion of the project results and recommendations

> The Tripartite Technical Committee (TTC) for SCSRs for its involvement in study discussions

> The research team members for their respective contributions (Ms Sophi Hlatshwayo, Mr Michael Sehlabana, Mr Wilfried Schreiber, Mr Schu Schutte, Mr Christo de Klerk, Mr John Sithole, Dr Johan Kielblock and Professor Lindiwe Zungu)

> Professor Hans de Ridder and his team of postgraduate students from North-West University for conducting the anthropometric measurements for the study

> Ms Renee Koen for conducting statistical analyses; and

> Mr Riaan Bergh for his guidance and management of the research group.

\section{References}

Afrox. 2014. Product data sheet: AfroxPac 35 Self-contained self-rescuer. http:// www.afrox-welding.co.za/en/safety_products/self_rescue/afroxpac/index.html [accessed 29 November 2019].

Anglo American. 2012. Women in mining: A health and safety perspective. Proceedings of the ICMM Health and Safety Conference, Santiago, Chile, 13-16 November 2012.

BaKri, I., LeE, J.Y., NAKAO, K., WaKabAYASH, H., and TochiHARA, Y. 2012. Effects of firefighters' self-contained breathing apparatus' weight and its harness design on the physiological and subjective responses. Ergonomics, vol. 55, no. 7 . pp. 782-791.

Borg, G.A. 1962. Physical performance and perceived exertion. Studia Psychologica et Paedagogica, Series altera, Investigationes XI. Gleerup, Lund, Sweden.

Coca, A., Kim, J-H., Duffy, R., and Williams, W.J. 2011. Field evaluation of a new prototype self-contained breathing apparatus. Ergonomics, vol. 54, no. 12 pp. 1197-1206.

CORLETT, E.N. and Bishop, R.P. 1976. A technique for assessing postural discomfort Ergonomics, vol. 19, no. 2. pp. 175-182.

DRÄGERSAFETy. 2010. Dräger Oxyboks K 35 Oxygen self-rescuer. http://www. a11supply.com/images/file/oxyboks_ds_9044881_en.pdf [accessed 29 November 2019].

Hodgskiss, J., Letsoalo, S., Sehlabana, M., Schreiber, W., Schutte, S., de Klerk, C., Sithole, J., Kielblock, J., and Zungu, L. 2017. Assessment of the ergonomics design of self-contained self-rescuer (SCSR) devices for use by women in mining. Project no. SIM 160902. Mine Health and Safety Council, Sandton, South Africa.

International Ergonomics Association. 2016. Definitions and domains of ergonomics. http://www.iea.cc/whats/ [accessed 29 November 2019]

ISO/CD 16900-5.2. Respiratory Protective Devices - Methods of Test and Test Equipment - Part 5: Breathing Machine/Metabolic Simulator/RPD Headforms/ Torso, Tools and Transfer Standards. Geneva.
ISO/TS 16976 2:2015. Respiratory Protective Devices - Human Factors - Part 2: Anthropometrics. Geneva.

ISO/TS 16976 8:2013. Respiratory Protective Devices - Human Factors - Part 2: Ergonomic Factors. Geneva.

Kowalski-Trakofler, K.M., Vaught, C. and Brnich JR, M.J. 2008. Expectations training for miners using self-contained self-rescuers in escapes from underground coal mines. Journal of Occupational and Environmental Hygiene, vol. 18, no. 10. pp. 671-677.

MSA. 2016. SavOx chemical oxygen self-rescuer. http://www.keison.co.uk/products/ msa/Savox.pdf [last accessed 29 Nov 19].

SANDSTRÖM, A. 2015. Improving self-rescue equipment. Bachelor's thesis, Umeå Institute of Design, Umeå University, Sweden.

SANS 1737:2008. South African National Standard - Body-worn escape type breathing apparatus. South African Bureau of Standards, Pretoria.

Schauenburg Lighting Technologies. 2013. Roxy 40 Self-contained self-rescuer. http:// www.dezega.com/sites/default/files/2017-09/\%D0\%A0\%D0\%AD_ROXY40.pdf [accessed 29 November 2019].

ScHReIBER, W.L. 1999. Self-contained self-rescuers in the South African mining industry - "Life saver or necessary evil"? Journal of the Mine Ventilation Society of South Africa, January/March. pp. 4-10.

Schrieber, W.L., VAn Zyl, F.J., AND BIFFI, M. 2003. Innovative concepts and developments for future generations of self-contained self-rescuers (SCSRs). CSIR, Miningtek.

Schreiber, L.W. and Sehlabana, M.M. 2015. Annual report on self-contained selfrescuer (SCSR) monitoring in the South African mining industry for the period January to December 2014. Report no. DMS COT Gen 17427-1. CSIR, Pretoria.

Schutte, P.C. 2005. Ergonomics in the South African mining industry. Journal of the South African Institute of Mining and Metallurgy, vol. 105, no. 6. pp. 360-372.

SchutTe, P.C. and JAmes, J.P. 2007. Ergonomics. Handbook on Mine Occupational Hygiene Measurements. Stanton, D.W., Kielbock, J., Schoeman, J.J., and Johnson, J.R. Mine Health and Safety Council (MHSC), Johannesburg. Chapter 23, pp. 299-310.

Schutte, P.C. and Shaba, M.N. 2003. Ergonomics of mining machinery and transport in the South African mining industry. Final Report. Project no. SIM020504 (EC 2003-0252). Safety in Mines Research Advisory Committee, Johannesburg.

South Africa. 1996. Mine Health and Safety Act, Act No. 29 of 1996. Department of Minerals and Energy, Pretoria.

South Africa. 2002a. Broad-Based Socio-Economic Empowerment Charter for the South African Mining Industry, Act No. 53 of 2003. Department of Minerals and Energy, Pretoria.

South AfricA. 2002b. Mineral and Petroleum Resources Development Act, Act No. 28 of 2002. Department of Minerals and Energy, Pretoria.

Stewart, A.D., Marfell-Jones, M.J., Olds, T., and De Ridder, J.H. 2011. International Standards for Anthropometric Assessment. ISAK, Lower Hutt, New Zealand.

Teeravarunyou, S. 2008. Usability testing of a self-rescue respiratory protective device. Proceedings of the 9th Southeast Asian Ergonomics Society Conference, Bangkok, Thailand, 22-24 October 2008. Ergonomics Society of Thailand. pp. 1-9.

Van Aardt, I., Bendeman, H., Christie, C., Gazi, S., and Schutte, P.C. 2008. Exploratory survey of women in mining in the South African mining industry with specific regard to but not limited to Occupational Health and Safety Issues. Project no. SIM080901. Mine Health and Safety Council, Sandton, South Africa.

ZunGu, L.I. 2012. Occupational health and safety challenges reported by women in selected South African gold and platinum mines. Occupational Health Southern Africa, vol. 18, no. 5. pp. 6-13.

ZunGu, L.I. 2013. South African guideline for the selection and provision of personal protective equipment for women in mining. Occupational Health Southern Africa, vol. 19, no. 3. pp. 4-9. 